\title{
COMERCIALIZAÇÃO E ORGANIZAÇÃO DOS PRODUTORES AGROECOLÓGICOS NO RIO GRANDE DO SUL - O ESTUDO DAS EXPERIÊNCIAS DA ASSOCIAÇÃO AGRICULTORES ECOLOGISTAS DE IPÊ E ANTONIO PRADO - AECIA E CENTRO DE APOIO AO PEQUENO AGRICULTOR - CAPA, DE SANTA CRUZ DO SUL
}

\author{
COMMERCIALIZATION AND ORGANIZATION OF \\ PRODUCERS AGROECOLOGIAL IN RIO GRANDE DO SUL \\ - THE STUDY OF EXPERIENCIES FAMERS ASSOCIATION \\ ECOLOGIST FROM IPÊ AND ANTÔNIO PRADO (AECIA) \\ AND THE SMALL FAMER SUPPORT CENTER - CAPA \\ FROM SANTA CRUZ DO SUL
}

Fabio Schwab do Nascimento

Instituto Federal do Pará - Belém - PA - Brasil

Paulo Roberto Beskow

Universidade Federal de São Carlos - Araras - SP - Brasil

\begin{abstract}
Resumo: Este trabalho busca, de forma preliminar, apresentar os resultados de pesquisa realizada como parte do curso de mestrado do Programa de Pós-Graduação em Agroecologia e Desenvolvimento Rural - PPGADR da Universidade Federal de São Carlos - UFSCar. Neste estudo, objetivou-se analisar os diferentes processos de comercialização e organização em agricultura ecológica existentes no Rio Grande do Sul em relação à concepção de organização de seus produtores e às formas de comercialização utilizadas. Para desenvolver o presente trabalho, será utilizado um estudo de caso, tendo como objeto duas experiências no Rio Grande do Sul. As experiências escolhidas foram a Associação Agricultores Ecologistas de Ipê e Antonio Prado (Ipê e Antonio Prado) e o Centro de Apoio ao Pequeno Agricultor (Santa Cruz do Sul). Realizou-se a análise socioeconômica destas experiências, observando-se de que forma as suas formas de organização e comercialização influenciam nos resultados alcançados.
\end{abstract}


Palavras-chave: Agroecologia. Comercialização. Agricultura familiar.

Abstract: This article in a preliminary way, to present the results of research conducted as parto $f$ de Master Course in Agroecology and Rural Development and University Federal de São Carlos from Brasil. This study to analyse the different processes of marketing and organization in existing farming in Rio Grande do Sul in relation to the concept of organization of producers and their forms of marketing used. To develop this work, we will use a case study, having as object experience two in Rio Grande do Sul. The experiments were chosen two in Rio Grande do Sul. The experiments were chosen Ipe environmentalists farms association and Antonio Prado (RS) and the Small Farmer Support Center (Santa Cruz do Sul/RS). We conducted a socioeconomic analysis of these experiments observing how their organization and marketing influence the results.

Keywords: Agroecology. Marketing. Family farming. 


\section{INTRODUÇÃO}

As experiências agroecológicas no Rio Grande do Sul se diferenciam devido à forma com que surgiram em relação a muitas outras experiências no país. No estado, sua formação, ligada às pastorais das igrejas católica e evangélica, assumiu contornos específicos de natureza social, política e filosófica. Além disso, possuem características diferenciadas tanto na organização da produção como nas formas de comercialização. No tocante à produção, privilegiam a organização de grupos, associações e cooperativas e, em relação à comercialização, priorizam as formas diretas de comercialização entre agricultor e consumidor, evitando-se, assim, a indústria e os atravessadores. Nesse sentido, no estado, destacam-se as feiras de produtores.

No Rio Grande do Sul, assim como nos demais estados da região sul do Brasil, além da certificação por agente externo, baseada em princípios e normas técnicas de produção da International Federation of Organic Agriculture Movements-IFOAM, há outras feitas pelo ECOCERT, IBD, TECPAR e IMO', que estão credenciadas pelo Ministério Agricultura, Pecuária e Abastecimento-MAPA. Mas, nos estados do sul, está sendo mais difundido o uso da certificação participativa por meio de Sistemas Participativos de Garantia - SPG e de Organismo Participativo de Avaliação de Conformidade - OPAC, que nesse caso, é realizada pela Rede Ecovida de Agroecologia - ECOVIDA.

Por meio desta análise, objetiva-se saber se os diferentes processos possuem capacidade de sustentação ao longo do tempo, inclusive, levando em conta as mudanças na relação produtorconsumidor que têm ocorrido nos últimos anos.

É importante destacar que, neste artigo, adota-se a definição de agroecologia como a ciência que apresenta uma série de princípios e metodologias para estudar, analisar, dirigir, desenhar e avaliar ecossistemas. (ALTIERI, 1998).

\footnotetext{
1 IBD - Instituto Biodinâmico

ECOCERT - Entidade francesa de certificação

TECPAR - Instituto de Tecnologia do Paraná

IMO - Instituto de Mercado Ecológico
} 
Segundo Altieri (1989), agroecossistema é a unidade fundamental de estudo, nos quais os ciclos minerais, as transformações energéticas, os processos biológicos e as relações socioeconômicas são vistas e analisadas em seu conjunto. Sob o ponto de vista da pesquisa agroecológica, seus objetivos não são a maximização da produção de uma atividade particular, mas a otimização do agroecossistema como um todo, o que significa a necessidade de uma maior ênfase no conhecimento, na análise e na interpretação das complexas relações existentes entre as pessoas, os cultivos, o solo, a água e os animais.

A agroecologia concebe os sistemas produtivos como agroecossistemas em que os ciclos minerais, as transformações energéticas, os processos biológicos e as relações socioeconômicas são investigadas e analisadas como um todo. E, na medida em que a agroecologia é um conjunto de conhecimentos em construção, está sempre levando em conta as transformações nos contextos naturais, sociais e políticos. (COSTABEBER, 1998).

\section{CONTEXTUALIZANDO A COMERCIALIZAÇÃO DE PRODUTOS ECOLÓGICOS NO RIO GRANDE DO SUL}

A origem da agricultura ecológica remete ao final dos anos 1970 e início dos anos 1980, em nível nacional e especialmente na região sul do Brasil, a partir das críticas ao padrão tecnológico implantado pela Revolução Verde. Junto a isso, foi se consolidando uma série de experiências e iniciativas destinadas a encontrar modelos tecnológicos menos agressivos ao meio ambiente e mais adequados às condições sociais e econômicas dos agricultores familiares.

$\mathrm{Na}$ década de 1980, cresceram os movimentos sociais e suas organizações, somando-se a eles algumas Organizações Não Governamentais-ONGs, como o CAPA, Centro Ecológico Ipê-CEI, Centro de Tecnologias Alternativas Populares-CETAP e Fundação gaia. A noção de "tecnologias alternativas" foi utilizada por muitas ONGs vinculadas à agricultura como o principal argumento contrário ao "pacote tecnológico" da agricultura convencional (...) buscando recuperar, experimentar e difundir tecnologias socialmente apropriadas aos pequenos agricultores. Já no começo dos anos 1990, constata-se um 
incremento do número de organizações de agricultores (clubes, associações de agricultores, grupos comunitários) interessados no processo de "ecologização da agricultura". (COSTABEBER, 1998).

Nesse contexto, a partir da década de 1990, é adotado o termo Agroecologia no Rio Grande do Sul como base epistêmica dos processos agrícolas, consolidando-se como referência alternativa ao modelo agrícola dominante no país. Essa adoção teve principalmente como motivo a adoção da Agroecologia como uma das formas de desenvolver a Agricultura Familiar no Governo Olívio Dutra (1998-2001) em que a Empresa de Assistência Técnica e Extensão Rural-EMATER/RS teve grande importância como forma de disseminar a agroecologia no Rio Grande do Sul.

As experiências de agroecologia no Rio Grande do Sul desenvolvem-se centradas nos seguintes objetivos: orientar, conscientizar, apoiar e acompanhar os pequenos agricultores por meio de reuniões, seminários com jovens, palestras e outras formas de atuação.

Fonseca \& Feliconio (2000) indicam, no entanto, a existência de duas concepções ideológicas conflitivas entre os partidários da agricultura ecológica. De um lado, os que querem desenvolver a agricultura ecológica influenciada pelos organismos de desenvolvimento e por empresas, visão muito expressiva nos estados de São Paulo e Rio de Janeiro, o que redundou na criação de associações de produtores nas diversas regiões do país a partir da segunda metade dos anos 1990. De outro, os que afirmam sua independência em relação a estes atores como as experiências no Rio Grande do Sul demonstram, muitas delas ligadas às opções defendidas pelas ONGs. Para estas, o papel dos seus técnicos é mais político e ideológico do que técnico (ALMEIDA, 1999), com as dificuldades técnicas e as questões econômicas mais concretas minimizadas. Nestas, por exemplo, predominam as informações e análises de natureza mais geral sobre os processos econômicos e de comercialização, muitas vezes, limitando-se o seu enfoque à afirmação de que os sistemas de produção sustentável têm um futuro garantido.

Outro aspecto que também pode visualizar-se na experiência gaúcha que a diferencia das de São Paulo e Rio de Janeiro é que, além da existência da certificação por agente externo baseada em princípios e normas do MAPA também há uma certificação baseada em processos de 
avaliação participativa, tais como desenvolvidos pelos sistemas OPAC e SPG.

Estudos como os de Costabeber (1998), Meirelles (2001), Storch et alii (2004), Schultz (2007) e Lovato (2007), entre outros, mostram a consolidação das feiras como o principal canal de comercialização dos produtos ecológicos no Rio Grande do Sul, sendo poucas as experiências oriundas de outras formas de comercialização. Até os anos 1990, essas feiras eram poucas e restritas a algumas capitais do centrosul do Brasil, mas, com o aumento do número de agricultores e principalmente dos consumidores de produtos ecológicos, estas se espalharam por outras regiões do país.

Uma das principais formas de comercialização de produtos agroecológicos usadas pelas ONGs no Rio Grande do Sul são as feiras, pois estas, além de estabelecerem uma relação direta entre o agricultor e o consumidor - o que é defendido pelo movimento agroecológico no estado - também possibilitam maiores ganhos ao agricultor e menor preço ao consumidor. Mas este tipo de comercialização direta enfrenta problemas e limitações devido às mudanças dos hábitos do consumidor que prefere fazer suas compras em estabelecimentos comerciais ou, valendo-se de outras formas não tradicionais, não se dispondo a ir às feiras. Esse fato pode ser verificado pelo forte aumento das vendas por meio das seguintes modalidades: entrega de cestas em domicílio para as cooperativas de consumidores urbanos de alimentos ecológicos; crescimento das pequenas lojas de produtos ecológicos e naturais/integrais; aumento da importância do mercado institucional compras do governo federal, estadual ou municipal - para abastecimento de estruturas de serviços públicos, em especial merenda escolar; e crescente peso das redes varejistas e de supermercados, as quais estão assumindo um papel de destaque na evolução do setor, o qual já contribui com $1 \%$ do total das vendas de produtos ecológicos no país. Em 2009, por exemplo, a rede Pão de Açúcar teve um crescimento sobre o ano anterior de $40 \%$ na venda de produtos orgânicos, que ocupam cada vez mais espaço nas suas gôndolas, criando a marca "Taeq" própria para produtos orgânicos. E, no Brasil, as vendas de produtos orgânicos alcançaram R\$350 milhões em 2010, com o valor de $40 \%$ superior ao registrado em 2009, conforme os números 
divulgados pelo Projeto "Organics Brasil", organização não governamental.

Embora proporção bastante significativa da produção brasileira de produtos ecológicos seja destinada ao mercado internacional, no mercado interno tem havido uma crescente importância das marcas de produtos orgânicos industrializados (e não apenas in natura) comercializadas em um número crescente de pontos de venda. (SILVEIRA, 2009; SILVEIRA, 2010).

Outro motivo para o aumento da venda de produtos orgânicos é a reestruturação pela qual está passando o setor de alimentos, acarretando novos tipos de relacionamento entre os agentes das cadeias produtivas, sendo importante para o segmento de produtos ecológicos analisar essas tendências para que consigam elaborar posicionamentos e alternativas estratégicas para a alavancagem das suas vendas e, principalmente, para que permaneçam neste mercado os atuais produtores, os quais foram os indutores iniciais de todo o processo.

Em tese de doutorado, Silveira (2010) demonstra que a viabilidade das experiências de agricultura ecológica no Rio Grande do Sul está calcada na possibilidade de serem utilizados diversos canais de comercialização, constituindo-se a diversificação de rotas até o consumidor o principal fator para a sua sobrevivência (vide tabela 01). Trata-se, segundo o autor, de compatibilizar os canais de comercialização direta com a venda para lojas especializadas, supermercados, exportação para mercados de comércio justo e para o mercado institucional.

De acordo com Assis (1993) e Junqueira \& Luengo (2000), o consumo de produtos originários da agricultura orgânica tem se caracterizado como um segmento diferenciado de mercado, no qual a segurança alimentar aliada ao não uso de agrotóxicos é decisiva na opção de consumo.

Estudos como o de Meirelles (2001) já demonstravam uma tendência no início da década de 2000 pela busca de canais longos de comercialização por meio de grandes redes de supermercados e exportação como uma das principais estratégias de vendas de produtos ecológicos. Contrariando essa tendência, algumas ONGs buscaram 
privilegiar os mercados locais para o escoamento de sua produção através dos canais curtos de comercialização.

Segundo Meirelles (2001), são vários os fatores que fazem muitos produtores agroecológicos utilizarem técnicas alternativas de produção ecológica, mas que, no processo de comercialização, optam pelo mercado convencional. Deles, podem-se destacar os seguintes: o acentuado crescimento do mercado de produtos ecológicos atraiu para o setor uma parcela de empresários rurais e urbanos, a maioria não identificada com o que aqui se denomina ideário agroecológico; a necessidade premente de reprodução econômica da agricultura familiar que obriga esse setor e seus aliados a buscarem alguma forma de inserção no mercado, muitas vezes, não acompanhada de reflexão sobre o papel desse mercado na construção de um desenvolvimento rural sustentável; e a falta de um maior apoio governamental para o redesenho das redes de comércio hoje estabelecidas - centralizadas e concentradas.

No entanto, é necessário notar que essa opção de algumas ONGs que prestam assessoria à produção ecológica - como por exemplo, o caso do Centro Ecológico Ipê e a AECIA - vem gerando conflitos com os agricultores e suas organizações, pois estes têm preferido buscar inserção em diferentes mercados para dar vazão a uma escala maior de produção em função do aumento da demanda por produtos diferenciados (SILVEIRA, 2010)

As feiras ecológicas são as estruturas de comercialização diretas que são geralmente utilizadas pelos agricultores gaúchos para escoarem sua produção, buscando, principalmente, a eliminação de intermediários, diminuindo, dessa forma, a apropriação da renda por parte de terceiros e as assimetrias de informações nas relações comerciais, sendo uma das melhores formas de comercialização alternativas ao mercado convencional.

Segundo Silveira (2010), esse é o discurso das ONGs prestadoras de assessoria que defendem a opção de formas alternativas de comercialização às convencionais. Nesse sentido, a utilização das feiras-livres para a comercialização de alimentos orgânicos constitui-se na alternativa praticamente imprescindível para a continuidade desse modo alternativo de produção agrícola. 
Para Schultz (2001), a feira tem como objetivo promover de forma pública a comercialização de alimentos orgânicos (humanização das relações comerciais), eliminando intermediários, estimulando a integração e a troca de experiências entre produtores, criando-se fortes vínculos entre os produtores e consumidores, resultando em uma certificação solidária dos que atuam na produção, industrialização, comercialização e nos serviços de apoio e assistência técnica.

O grande problema da comercialização em feiras, segundo Schultz (2001), é que este tipo de estratégia demanda dos produtores um grande esforço, pois, ao mesmo tempo em que precisam de mais tempo na lavoura para aumentar a produção e atenderem à demanda crescente, precisam também dispor de um tempo maior nas feiras para comercializar seus próprios produtos, já que a quantidade de produtos e o número de locais de venda naturalmente aumentam. Esse fato se torna um dilema para o produtor de alimentos ecológicos que, visualizando o mercado em expansão e a necessidade de aumentar a escala de produção, precisa também atender uma ou outra atividade relacionada ao processo de comercialização. Essa atividade, mesmo quando feita no sistema de rodízio com outros produtores, torna-se um limitador à expansão dos negócios.

Pode-se afirmar, portanto, que mudanças estão ocorrendo no mercado de produtos ecológicos, onde novos canais de comercialização estão, aos poucos, sendo exigidos pelos consumidores e pelos produtores rurais. Estes desejam aumentar a escala de produção à medida que o mercado cresce e quando passam a ter um melhor domínio sobre as novas técnicas agroecológicas de produção.

\section{CARACTERIZAÇÃO DA ÁREA DE ESTUDO}

A área estudada na experiência da AECIA situa-se nos municípios de Ipê e Antônio Prado a qual, segundo o Instituto Brasileiro de Geografia e Estatística-IBGE, integra a Microrregião de Vacaria. Localiza-se na transição entre a encosta basáltica do Planalto Meridional (mais conhecida como Serra Gaúcha) e os chamados Campos de Cima da Serra. A vegetação desses municípios caracteriza-se por uma interação entre a Mata de Araucárias, ou Floresta Ombrófila Mista, a Floresta 
Estacional Decidual e os Campos. O clima é classificado como subtropical úmido, em transição para o temperado, sendo marcado por invernos bastante rigorosos em comparação com outras partes do Brasil. Os índices de pluviosidade oscilam entre 2.000 e $2.500 \mathrm{~mm}$ anuais, com possibilidade de estiagem no verão. No inverno, a temperatura média fica em torno de $10^{\circ} \mathrm{C}$. (Macrozoneamento agroecológico e econômico do Estado do Rio Grande do Sul).

A topografia dos municípios é bastante acidentada, com altitudes que variam de $400 \mathrm{~m}$ acima do nível do mar nas ribanceiras do Rio das Antas, até acima de $800 \mathrm{~m}$ nas áreas de campo do município. Os solos são de origem basáltica, com textura predominantemente argilosa e possuem um bom potencial de fertilidade. Os solos, no geral, são ácidos ( $\mathrm{pH}$ médio de 4,5), com alto teor de alumínio e com limitações no que diz respeito à mecanização, sobretudo devido à sua declividade. (SCHIMITT, 2001).

A economia dos municípios é baseada na agropecuária, com predomínio da agricultura familiar praticada em pequenas propriedades de até 20 ha. A agricultura é bastante diversificada com um nível médio de capitalização, com os sistemas de produção integrando produção vegetal e animal, destacando-se a fruticultura, a olericultura ecológica, a pecuária leiteira e de corte, bem como a produção de suínos e aves.

Situada nessa região, a Cooperativa da Associação dos Agricultores Ecologistas de Ipê e Antônio Prado-COOPAECIA ocupa o $28^{\circ}$ lugar na arrecadação de tributos no Município de Antônio Prado, particularmente devido ao grande volume de suco de uva e molho de tomate ecológico produzidos e comercializados. (IBGE, 2006).

Por outro lado, a atuação do CAPA se dá no Município de Santa Cruz do Sul, localizado no Vale do Rio Pardo, com uma população de 118.374 habitantes e com um Produto Interno Bruto-PIB de $\mathrm{R} \$ 3.287 .130 .000$, com a agropecuária participando com $4,52 \%$ no PIB deste município, seguida da indústria $(43,77 \%)$ e do setor de serviços (51,71\%).(IBGE, 2006)

Essa região foi colonizada, na grande maioria, por alemães, sendo que a principal cultura agrícola é o fumo, o qual abastece o maior complexo beneficiador de fumo do Brasil. Esse município industrializa cerca de 13.967 toneladas de fumo/ano e possui em torno de 3.411 
propriedades rurais, com média de 2,6 hectares de extensão, totalizando 6.535 hectares cultivados com fumo. Há uma fortíssima presença das indústrias do fumo na produção de sua matéria-prima, por meio da garantia da compra atrelada ao apoio técnico e financeiro, bem como da existência de programas sociais destinados aos fumicultores. Dessa forma, foi criado sólido sistema de trocas e lealdades entre a maior parte dos fumicultores e a indústria fumageira.

\section{METODOLOGIA USADA NA PESQUISA}

A escolha do método foi condicionada pelos objetivos propostos, possuindo um caráter exploratório, já que é necessário buscar um maior conhecimento sobre o tema ou problema de pesquisa. Mattar (1993) afirma que todas as pesquisas têm aspectos exploratórios, e são raras aquelas cujo problema de pesquisa e (ou) objetivos estejam tão bem definidos que possam prescindir de atividades de pesquisa exploratória.

Sampieri et alii (1994) afirmam que a escolha do método de pesquisa depende de dois fatores principais: o estado do conhecimento do tema investigado na literatura e o enfoque que o investigador pretende dar ao seu estudo. Ou seja, define o estudo como exploratório quando o seu objetivo é examinar um tema ou problema de investigação pouco estudado ou que tenha sido pouco abordado. $\mathrm{E}$ também define o estudo como exploratório quando o enfoque de uma pesquisa é original. Nesse sentido, o presente estudo pode ser considerado como exploratório em virtude das experiências agroecológicas no Rio Grande do Sul serem diferenciadas das demais experiências encontradas no país, e ainda estarem pouco disponibilizadas informações para uma melhor compreensão dos fenômenos que ocorrem nesta região do país.

Com relação ao método de pesquisa mais adequado ao caráter exploratório do atual estudo, Lazzarini (1997) afirma que novas linhas de pesquisa em ciências sociais têm buscado considerar aspectos mais gerais de um problema, tornando a abordagem mais contextual, sendo que, dentre os métodos qualitativos, o estudo de caso é muito útil a este enfoque, pois o seu principal objetivo é contextualizar e aprofundar o estudo do problema. Assim sendo, esse tipo de método de pesquisa 
se encaixa muito bem na análise abrangente e complexa que se pretende realizar.

De acordo com Yin (1990), o método do estudo de caso é uma pesquisa empírica em que múltiplas fontes de evidência são utilizadas e que investiga um fenômeno contemporâneo inserido em seu contexto real, quando não existe uma clara fronteira entre o fenômeno e o contexto. Essas características do estudo de caso são totalmente adequadas a esta pesquisa e serão utilizadas várias fontes de dados e informações.

A pesquisa procura avaliar a capacidade de sustentação e os limites das experiências agroecológicas no Rio Grande do Sul a partir da análise das suas características de organização e comercialização.

Com o objetivo de melhor justificar a escolha deste método de pesquisa, será utilizada a sequência de passos proposta por Yin (1990) para a definição da estratégia de estudo, analisando-se os seguintes elementos inerentes ao problema a ser pesquisado:

1) Tipo de questão de pesquisa: a estratégia de estudo de caso presta-se a responder às perguntas de como $e$ por que certos fenômenos ocorrem. Retomando a definição do problema e objetivos, este estudo busca responder como e por que as experiências agroecológicas no Rio Grande do Sul possuem esse tipo de organização e comercialização - bem como o seu contexto institucional - como forma de levantar subsídios para o entendimento dos fenômenos e, portanto, responder às perguntas associadas ao problema.

2) Requer controle sobre os eventos comportamentais?: Para a pesquisa se enquadrar em estudo de caso, a resposta a esta pergunta deve ser não. No presente trabalho, não se busca e nem é necessário controle sobre os eventos analisados para entender os fenômenos pesquisados.

3) Está focada em eventos contemporâneos?: Para a pesquisa se enquadrar em estudo de caso a resposta a esta pergunta deve ser sim. Neste trabalho fica claro o foco em eventos contemporâneos.

Portanto, seguindo as definições de Yin (1990), a melhor estratégia de pesquisa para o presente trabalho é o estudo de caso, justificado acima. 


\subsection{Procedimentos metodológicos}

No presente trabalho, será utilizada para estudo de caso uma pesquisa quantitativa e qualitativa envolvendo experiências agroecológicas do Rio Grande do Sul.

As experiências escolhidas foram a AECIA e CAPA por englobarem diferentes formas de comercialização de produtos de base ecológica.

A AECIA foi fundada em 1989. Surge a partir das discussões estimuladas pela Pastoral da Juventude Rural da Igreja Católica de Antônio Prado/RS e pelo Centro de Agricultura Ecológica de Ipê/RS, tendo em vista os problemas causados pela agricultura industrial e pela poluição ambiental causada pela utilização de máquinas e insumos de origem industrial, como também pelo empobrecimento dos agricultores e o consequente êxodo rural.

O trabalho da AECIA e as suas conquistas têm servido de referência para inúmeros grupos de agricultores familiares e técnicos interessados na agricultura ecológica. Ao longo de sua existência, a AECIA recebeu dezenas de estagiários e centenas de visitas nas propriedades de membros do grupo, além de ser convidada para ministrar palestras em diversos locais do Brasil e do exterior.

Já o CAPA iniciou suas atividades no ano de 1987, com a transferência para Santa Cruz do Sul do escritório que tinha em Arroio do Tigre. Essa transferência foi motivada por duas razões básicas: a necessidade de estar em um centro maior e o início de um intenso trabalho com grupos de agricultores das localidades de Alto Castelhano, Fontoura Gonçalves e Boa Esperança - então pertencentes a Santa Cruz do Sul, hoje, ao município Vale do Sol - resultando a atuação destes grupos na criação da União Serrana de Agricultores. Outras frentes de trabalho dessa época foram o apoio ao Movimento de Atingidos por Barragens-MAB, no Município de Dona Francisca, e o trabalho com o resgate das sementes de milho de variedades crioulas nos municípios de Ibarama e Dona Francisca.

\section{A EXPERIÊNCIA ASSOCIAÇÃO DOS AGRICULTORES ECOLOGISTAS DE IPÊ E ANTONIO PRADO - AECIA}


Teve sua formação ligada à Comissão Pastoral da Terra-CPT e ao Centro Ecológico IPÊ (RS), por meio da iniciativa de algumas pessoas que passaram a adotar uma agricultura alternativa ao modelo da agricultura convencional anteriormente existente na região.

Essas pessoas já tinham, nas suas propriedades, uma produção diversificada, particularmente uva e hortigranjeiros. Nesse caso, a opção pela agricultura alternativa resultou da experiência acumulada de alguns agricultores de que a agricultura que praticavam não era sustentável economicamente e também danosa para a saúde, tanto para o agricultor e o consumidor como para a natureza devido ao uso na sua produção de todo o tipo de agroquímicos. Por esse motivo e com a ajuda de profissionais, buscou-se uma nova agricultura que respeitasse tanto o agricultor quanto o consumidor e a natureza.

A escolha dos agricultores da AECIA por uma agricultura ecológica foi motivada porque estes queriam encontrar uma alternativa ao modelo de agricultura a que estavam vinculados. Por meio da ajuda da CPT e do Centro Ecológico Ipê, a escolha deu-se por uma agricultura de base ecológica que estava de acordo com os princípios desses agricultores, baseados num tipo de produção direcionada à sustentabilidade socioeconômica dos produtores, à sustentabilidade dos recursos naturais e à saúde dos agricultores e consumidores.

O principal problema enfrentando pela AECIA no seu início foi em relação à comercialização dos produtos, pois não possuíam um local para a venda de sua produção. Nesse momento, a ajuda do CEI foi muito importante, tendo conseguido um ponto para comercialização na Feira Ecológica administrada pela Coolmeia, que era realizada em Porto Alegre. Outro problema que a AECIA enfrentou nesta época foi relacionado à assistência técnica, já que, naquela época, a EMATER não acreditava que uma agricultura ecológica fosse possível. Esse problema foi sanado pelos técnicos do CEI que deram o suporte necessário aos agricultores.

$A$ experiência da AECIA começou, inicialmente, com a comercialização de seus produtos na Feira da Agricultura Ecológica-FAE, administrada pela Coolmeia em Porto Alegre. Por meio dessa comercialização, começaram a surgir outros canais de comercialização no estado através de lojas macrobióticas. 
O ano de 1992 foi muito importante para a AECIA, quando surgiu a oportunidade de fazer uma feira no Estado de São Paulo, por meio de um convite da Associação de Agricultura Orgânica-AAO, abrindo-se, então, um mercado fora do Rio Grande do Sul, sendo que esta comercialização era feita por meio de um representante.

Naquela época, também começa a industrialização de alguns produtos, principalmente sucos de uva, amora, framboesa, maça e pêssego. Isso ocorreu porque a produção in natura era maior do que a demanda na região, muitas vezes, obrigando a venda do produto no mercado convencional, o que trazia desvantagens financeiras para os agricultores em virtude da diferença de preços entre os produtos convencionais e os ecológicos. Então, com a industrialização desses produtos, além da vantagem representada pela agregação de valor, não se teria mais que vendê-los como convencionais ou, até mesmo, perdêlos devido à perda de seus prazos de validade.

Com o sucesso de venda desses produtos industrializados, aumentou a sua diversificação, passando, também, a incorporar extratos e doces. Esses produtos, além de serem vendidos na $F A E$, também passaram a ser comercializados nos estados de São Paulo (AAO) e Rio de Janeiro-Cooperativa de Produtores de Alimentos Naturais-COONATUR.

Diferentemente da experiência do CAPA, que trabalhava com a comercialização em circuitos curtos, a AECIA procurou também trabalhar com os circuitos longos de comercialização por meio dos chamados representantes.

Como a venda de produtos industrializados para fora do estado exigia o Cadastro Nacional Pessoa Jurídica-CNPJ, foi criada uma cooperativa para atender a esta exigência legal.

Os produtos comercializados pela COOPAECIA são os seguintes: sucos integrais de uva, amora, tomate, maçã e maracujá; néctares de maracujá, uva, pêssego, amora, framboesa, maçã e goiaba; molho e extrato de tomate; doce de amora; amora em calda; conserva de pepino; geléia de maçã; uva-passa sem açúcar; banana-passa e tomate seco. Em relação à produção, atualmente as 4 (quatro) unidades dessa cooperativa apresentam registro sanitário e uma capacidade instalada de processamento de $100.000 \mathrm{~kg}$ de uva/unidade, com o processamento em média de $50.000 \mathrm{~kg}$ de uva/unidade/ano. 
A partir de 2007, teve início a comercialização por meio da rede Pão-de-

Açúcar, destinando-se $50 \%$ da produção de 2008 para as suas lojas. Essa relação com o grupo Pão-de-Açúcar é avaliada como muito importante, considerando-se o grande volume comercializado, o que compensa o desconto de $14 \%$ no preço de entrega. As entregas são mensais e o pagamento com prazo de 50 dias, o que é considerado normal em transações com supermercados.

No que diz respeito às agroindústrias, inicialmente era somente uma legalizada e os produtos dos agricultores eram feitos por ela. Atualmente existem cinco agroindústrias que levam a marca da cooperativa, mas são individuais ou coletivas, sendo que, quem faz a comercialização é a cooperativa. É descontado, por venda, um valor de $12 \%$ para as despesas da cooperativa.

Em relação à feira, o primeiro ponto de venda da $A E C I A$ foi na feira organizada pela COOLMEIA em Porto Alegre e, depois, se expandiu-se para a cidade de Caxias do Sul. Hoje, esses pontos continuam com a associação e são divididos em grupos por comunidade.

Em relação ao papel da feira na AECIA é que esta é um local de encontro entre o agricultor e o consumidor, onde se pode ter uma análise de produtos e tendências. Outra razão é que, na feira, o agricultor dispõe de dinheiro à vista, não necessitando esperar o pagamento pela cooperativa.

De acordo com a transcrição de entrevista realizada entre abril e setembro de 2009 com fundadores e funcionários da AECIA e COOPAECIA.

A cooperativa no caso da AECIA nasceu de uma necessidade para venda de produtos para fora do Estado do Rio Grande do Sul.

Desde o seu início, a experiência da AECIA baseou-se em um trabalho coletivo junto aos agricultores, sempre trabalhando com grupos, os quais também são responsáveis pela participação da associação nas feiras. Os participantes de cada grupo dividem as tarefas entre si e, em cada edição da feira, cada um, em sistema de rodízio, é responsável pelo transporte dos produtos da área rural até o local de comercialização. 
Já a COOPAECIA tem uma estrutura semelhante à das cooperativas agrícolas tradicionais, com a assembleia geral reunida mensalmente, constituindo-se no seu órgão decisório máximo. O seu organograma tem como órgão máximo uma coordenação composta de quatro associados, com as funções de coordenador e vice, secretário e suplente. Também possui uma comissão de ética - composta por três sócios eleitos em assembleia - com a responsabilidade de atuar nas relações entre associados e consumidores.

$\mathrm{Na}$ AECIA, a comercialização se dá por meio de feiras, mercados tradicionais (lojas de produtos naturais, mercados, grandes redes de comercialização - Zaffari, Pão-de-Açúcar) e também cestas de produtos ecológicos. Atualmente, a AECIA comercializa 35 produtos diferentes, com destaque para os processados derivados de tomate (molho e extrato de tomate temperado) e de uva (suco de uva). $\mathrm{Na}$ comercialização por meio da feira, tem mais importância o contato do agricultor com o consumidor do que propriamente sua importância em termos do total de suas vendas. Assim como no CAPA, as feiras feitas pela AECIA em Caxias e Porto Alegre também são feitas por grupos de famílias, trabalhando em um espaço pertencente à AECIA. O transporte é feito pela própria associação, que cobra $12 \%$ sobre o valor das vendas. Na feira de Caxias do Sul, o transporte é por conta dos grupos, mas é cobrada uma taxa de $3 \%$ pela AECIA. Cabe evidenciar que a COOPAECIA baseia a sua estratégia de crescimento na busca de novos mercados, como por exemplo, os mercados institucionais, pretendendo também começar a industrializar novos produtos.

Já a forma de atuação da AECIA, embora também trabalhe com as feiras, baseia-se nos circuitos longos de comercialização, também vendo nos mercados institucionais uma outra forma de inserção de seus produtos no mercado.

No que diz respeito aos impactos da legislação dos produtos orgânicos, inicialmente houve, por parte da AECIA, um questionamento do porquê de fazer-se uma certificação dos orgânicos visto que o produto convencional traz sérios problemas à saúde do consumidor e, no entanto, não necessita de legislação semelhante. Depois, a associação participou da construção da REDE ECOVIDA que iria trabalhar com a questão de uma certificação participativa por meio de um OPAC. 
Ademais, por exigência do mercado, principalmente por parte das grandes redes de supermercados, também teve que adotar uma certificação por agente externo, no caso a francesa ECOCERT.

Já em relação à experiência da $\mathrm{AECIA}$, o principal ponto de estrangulamento é a falta de matéria-prima (uva), pois a produção dos associados não é suficiente para atender à demanda da agroindústria da cooperativa. Em função disso, impõe-se a necessidade de se conseguir parcerias externas, o que é bastante dificultado pela forte demanda de outros compradores por uva produzida de forma ecológica.

A assistência técnica inicialmente era feita pelo CEl. Atualmente, os próprios agricultores se auxiliam. A ideia é de contratar um técnico e um agrônomo para procurar novos produtores e parcerias. Para a cooperativa, há um enólogo que assina a parte industrializada. A EMATER presta assistência na parte de financiamentos junto ao Programa Nacional de Fortalecimento da Agricultura Familiar-PRONAF.

\section{A EXPERIÊNCIA DO CAPA}

Surgiu no ano de 1987 no seio da Igreja Evangélica de Confissão Luterana no Brasil-IECLB devido à crise que ocorria no setor de fumicultura, fazendo com que muitas famílias fossem excluídas do sistema de integração com a indústria fumageira. Dessa forma, foram buscadas alternativas para que estas famílias continuassem no campo e não tivessem que ir para a cidade. A solução encontrada foi por meio de uma agricultura alternativa de base ecológica como forma de fazer com que essas famílias não ficassem dependentes da cadeia agroindustrial do fumo.

Para o CAPA, sem essa mudança não haveria solução para essas famílias continuarem no campo. A primeira forma de implantação foi por meio de um processo de diálogo com essas famílias, apresentando o que era o CAPA, sua forma de trabalhar para, depois, com o aceite da comunidade, começar a trabalhá-las de forma coletiva por meio de grupos.

O principal problema enfrentado junto aos agricultores foi a desconfiança, se uma agricultura alternativa era mesmo a solução, pois eles viam este tipo de agricultura vinculada a pessoas pobres e não a 
eles. Também houve a oposição e resistência das fumageiras ao CAPA, por trabalhar com uma forma diferente de agricultura, que poderia trazer problemas futuros a este setor agroindustrial.

Como demonstram Meirelles (2001), Schimitt (2002), Storch et al.(2004), Schultz (2007) e Lovato (2007), a questão que envolve a constituição do mercado para a comercialização de produtos ecológicos é um dos principais problemas enfrentados pela produção de base ecológica, e como, na região, ele existia somente para o produtor de fumo, a produção inicialmente foi comercializada junto ao sistema educacional, sendo usado na merenda escolar das creches.

Para Costabeber (1998), Meirelles (2001), Storch et al. (2004), Schultz(2007) e Lovato (2007), uma outra forma de comercialização de produtos é por meio de feiras como a realizada pelo CAPA no Município de Santa Cruz do Sul onde a produção de hortigranjeiros, arroz, feijão e outros produtos não perecíveis era comercializada.

Com o passar do tempo, somente a feira não foi suficiente para escoar a produção das famílias, como evidenciam os estudos de Meirelles (2001) e Silveira (2010). Por este motivo, foi iniciado um processo para escolha da forma jurídica a ser usada. A opção escolhida foi a cooperativa, embora os agricultores, a princípio, tivessem receio em trabalhar com ela porque tiveram experiências mal sucedidas no passado. Assim foi fundada, em 2000, a Cooperativa ECOVALE que tinha como função principal fazer o escoamento dessa produção por meio de circuitos curtos e mercados institucionais para a venda do excedente que sobrava da venda nas feiras. Mesmo com o sucesso da cooperativa, a feira continuou com uma importância muito grande para o CAPA.

A comercialização dos produtos, hoje, dá-se por meio de várias formas, como feiras, venda a mercados locais, merenda escolar e convênios com outras cooperativas. A cooperativa trabalha com a produção de diversos produtos, entre eles: hortifrutigranjeiros, arroz, erva-mate, mel, derivados de cana-de-açúcar, cereais, bolachas, sucos e conservas.

Em relação à organização dos agricultores, ela ocorre de uma forma coletiva. O principal problema em se trabalhar de forma comunitária que teve que ser enfrentado pelo CAPA é que os agricultores vinham de um modelo de agricultura que era praticado 
individualmente, não tendo nenhuma experiência de trabalho em grupo. No entanto, com o tempo, esses problemas foram encaminhados de modo positivo.

Atualmente, o CAPA atua por meio de diversas formas de organização comunitária, desde aquelas que ainda se encontram em um estágio bastante embrionário - ainda não conseguiram formar uma associação e dependem de um técnico do centro para auxiliar na sua organização - até aquelas que já se constituem em associações e, nestas, a função do técnico é de assessorar nas questões de produção e comercialização. No tocante à cooperativa, o CAPA não interfere em seu funcionamento, cabendo-Ihe as funções de assessoria técnica, contábil e de órgão consultivo dos associados.

A estratégia de comercialização do CAPA objetiva atingir o máximo de canais de comercialização, desde as feiras até os canais curtos e os mercados institucionais. O interesse do centro pela comercialização em feiras fundamenta-se em uma questão doutrinária, já que é o único canal em que ocorre um contato direto entre o agricultor e o consumidor. Entretanto, como demonstram estudos de Schimitt (2002) e Schultz (2007), as feiras estão perdendo o espaço como única forma de comercialização de produtos ecológicos por não conseguirem escoar toda a produção dos agricultores.

Em Santa Cruz do Sul, as feiras são realizadas nas manhãs das quintas-feiras e dos sábados e às terças-feiras à tarde. Em Venâncio Aires ocorrem às terças-feiras e aos sábados, sempre pela manhã. Em Passo do Sobrado, às sextas-feiras pela manhã e em Cachoeira do Sul, aos sábados também pela manhã. Cabe registrar que as feiras de Santa Cruz do Sul e Venâncio Aires estão ligadas à ECOVALE.

Nas feiras sobressai a comercialização de hortigranjeiros, enquanto os demais produtos são vendidos, principalmente, nos demais canais de comercialização.

A ECOVALE surge como forma de comercializar o excedente das feiras. Primeiro, por meio de uma loja na cidade de Santa Cruz do Sul que servia de entreposto, depois, os produtos também vão para parceiros dentro da REDE ECOVIDA e para a alimentação escolar.

A ECOVALE trabalha com a venda de arroz, diversos tipos de feijão, açúcar mascavo, mel, erva-mate, gergelim, bolachas, 
hortifrutigranjeiros, entre outros. Comercializa seus próprios produtos tanto em uma loja própria no Município de Santa Cruz do Sul como na rede local de supermercados, nos mercados da cooperativa Languiru e, também, nos mercados institucionais representados pelas prefeituras da região. Estes últimos constituem-se no seu alvo principal para $o$ aumento de suas vendas.

Em relação com o mercado, a experiência do CAPA sempre evitou trabalhar em circuitos longos de comercialização. A ECOVALE tem como uma das suas estratégias trabalhar somente em canais curtos de comercialização, procurando parcerias com mercados e lojas de inserção local, dentro do propósito de fortalecimento das redes locais de comercialização, a partir de uma visão de economia solidária e comércio justo. E isso tem levado a cooperativa a obter muito sucesso, pois os seus produtos são bastante aceitos pelos supermercadistas locais que veem na compra dos produtos oriundos da região do Vale do Rio Pardo uma estratégia de marketing para as suas empresas. Outro canal de comercialização dos produtos da ECOVALE é o representado pelos mercados da Cooperativa LANGUIRU.

Uma das principais dificuldades encontradas pelo CAPA situa-se no fato de que atua numa região onde toda a estrutura da produção e da comercialização está organizada em função da produção de fumo, o que dificulta a ampliação da área destinada à produção de produtos ecológicos, com reflexo na sua evolução, que tem sido lenta e gradual. Esse pequeno volume de produção tem limitado a sua entrada em supermercados em virtude das dificuldades de competir em preços com os concorrentes. Além disso, ainda é fraca a conscientização do consumidor em relação às vantagens do consumo de alimentos produzidos ecologicamente. Outro ponto de estrangulamento é o representado pela questão tributária, já que o Imposto sobre Circulação de Mercadorias e Prestação de Serviços-ICMS incidente sobre a ECOVALE é muito alto.

O impacto da nova legislação voltada aos produtos orgânicos sobre a associação/cooperativa/rede para o CAPA tem representado mais um peso para os agricultores familiares em decorrência das novas exigências burocrático-legais. Todo o processo produtivo e de comercialização tem que ser adaptado a esse novo contexto institucional, além do investimento necessário para a construção de 
barreiras fitossanitárias, cruciais para evitar que os agrotóxicos usados na produção de fumo contaminem a produção ecológica, pois na região de atuação do CAPA predomina a agricultura familiar, caracterizada pela grande proximidade entre as propriedades. A essa situação se soma a questão do custo de manter-se a documentação para o uso do selo que garante que o produto é orgânico, cabendo notar que, no caso das feiras, não há necessidade de certificação dos produtos ecológicos por parte do MAPA. Já no caso da certificação, é feita pela própria ECOVIDA.

\section{CONCLUSÃO}

Este artigo procurou demonstrar que a atuação da AECIA e do CAPA na venda de produtos orgânicos no Rio Grande do Sul ocorre tanto em canais de comercialização curtos como longos. Em ambas as experiências estudadas, ficou demonstrado que somente a feira não consegue escoar toda a produção dos agricultores ecológicos, necessitando de outros canais de comercialização para a sua venda.

Desse modo, tanto a AECIA, por meio da comercialização em canais longos, como o CAPA, com a utilização de canais curtos de comercialização, têm buscado diversificar os locais de venda para atender à produção excedente dos agricultores e também para obter um melhor preço para os seus produtos.

Em função dessa mudança na sua estratégia de comercialização, a experiência da $A E C I A$ revela uma singularidade, já que no inicio de suas atividades, sob a orientação da assessoria do CEI entendia-se que somente a feira e o comércio local seriam suficientes para os agricultores venderem seus produtos. No entanto, com o surgimento de outros mercados para comercialização, a AECIA acabou se distanciando do CEl por entender que esses outros mercados seriam melhores locais de venda para seus produtos, tanto em termos de logística de localização como pelo fato de proporcionarem um preço de venda melhor para os seus produtos.

Um dos fatores explicativos para essa mudança de orientação da AECIA é o grau de instrução dos seus agricultores, pois, na sua maioria, possuem curso superior, enquanto que a maior parcela dos produtores rurais do CAPA não tem nem o ensino fundamental completo. Outro 
fator explicativo relaciona-se à certificação dos produtos, já que, enquanto a AECIA trabalha com a ECOVIDA e com a ECOCERT, o CAPA trabalha somente com a ECOVIDA, o que lhe traz dificuldades para entrar em alguns tipos de mercado. Outra dificuldade enfrentada pelo CAPA está relacionada à particularidade de localizar-se em uma região de predomínio da produção de fumo, baseada num sistema integrado com o complexo agroindustrial multinacional fumageiro, que dispõe de imensos recursos financeiros e tecnológicos para "competir" pelo agricultor.

Como conclusão final, cabe enfatizar que, embora as duas experiências analisadas tenham estratégias distintas de comercialização para os seus produtos, têm demonstrado capacidade de sustentação de suas atividades ao longo do tempo até os dias de hoje.

\section{REFERÊNCIAS}

ALMEIDA, Jalcione. A Agroecologia entre o movimento social e a domesticação pelo mercado. Disponível em <http://revistas.fee.tche.br/index.php/ensaios/article/viewFile/734/98 6>. Acesso em: 05 ago. 2007

A construção social de uma nova agricultura: tecnologia agrícola e movimentos sociais no sul do Brasil. Porto Alegre: Ed.UFRGS, 1999.

Agricultures alternatives, entre autonomie politique et ghettoïsation. In Zanoni, M. et Lamarche, H. (coord). Agriculture et ruralité au Brésil; un autre modèle de développement. Paris: Karthala, 2001.

ALTIERI, Miguel A. Agroecologia: as bases científicas da agricultura alternativa. 1.ed. Rio de Janeiro: AS-PTA, 240 p, 1989.

ALTIERI, M.A.; HECHT, S.B. Agroecology and small farm development. Boca Raton: CRC Press, 1989

ANGULO, José Luis Gutiérrez. Mercado local, produção familiar e desenvolvimento: estudo de caso da feira de Turmalina, Vale do 
Jequitinhonha, MG, Revista de Administração da UFLA, Lavras, São Paulo, p. 96-109, Jul/Dez., 2003.

ARL, Valdemar. Agroecologia: uma proposta em construção. Agroecologia em Santa Catarina. 1(2), 20-23, 1999.

ARL, V.; M., N.J. Agroecologia e certificação. (mimeo; Comunicação apresentada ao IV Encontro da Agricultura Familiar do Sul do Brasil). Esteio, RS, 4 p., 2000.

ASSIS, Renato Linhares de. Diagnóstico da agricultura orgânica no Estado do Rio de Janeiro e propostas para sua difusão. 1993. $154 \mathrm{f}$. Dissertação (Mestrado em Agronomia) - Universidade Federal Rural do Rio de Janeiro, Itaguaí, RJ, 1993.

BADALOTTI, Rosana Maria. A cooperação agrícola e agroecologia como base para a viabilização da agricultura familiar no oeste catarinense: 0 papel da APACO (Associação dos Pequenos Agricultores do Oeste Catarinense) e demais agentes sociais. 387f. Tese (Doutorado em Interdisciplinar em Ciências Humanas) Universidade Federal de Santa Catarina. Florianópolis, SC, 2003.

BALERINI, Heladio. Método para implementação de cadeia produtiva para a comercialização de produtos orgânicos. 167f. Dissertação (Mestrado Engenharia da produção) Universidade Federal de Santa Catarina. Florianópolis, SC, 2005.

BITTENCOURT, G.A.; DI SABBATO, A. Novo retrato da agricultura familiar: o Brasil redescoberto. Brasília: MDA/INCRA, 2000.

BRANDENBURG, A. Agricultura familiar, ONG's e desenvolvimento sustentável. Curitiba: Ed.UFPR, 1999.

BYÉ, P.; Schmidt, W. et al. Transférabilité des systèmes de certification des techniques locales/. Montpellier-Limoges. (Projeto de Pesquisa Fonds commun INRA-CIRAD 2001/02). Trabalho apresentado ao workshop Les formes sociales d exercice des activités agricoles à 1 
épreuve de la modernité avancée, do XIX Congresso da European Society for Rural Sociology, Dijon (França), 3-7, setembro de 2001. Tradução de Vanice Dolores Bazzo Schmidt.

CAMPANHOLA C; VALARINI PJ. A agricultura orgânica e seu potencial para o pequeno agricultor. Cadernos de Ciência \& Tecnologia 18: 69101. 2001.

CETAP - Centro de tecnologias alternativas populares. Construindo uma metodologia para o desenvolvimento rural sustentável. In Almeida, J.; Navarro, Z. (org.). Reconstruindo a agricultura: idéias e ideais na perspectiva do desenvolvimento rural sustentável. Porto Alegre: EdUFRGS, 1997.

COSTA NETO, Canrobert Penn Lopes. Ciência e saberes: tecnologias convencionais e agroecologia. Agroecologia e Desenvolvimento Sustentavel. Porto Alegre, RS v.1, n.2., 2000

COSTA NETO, C. Agricultura não-convencional, biodiversidade e sustentabilidade: a alternativa agroecológica. In: Froechlich, José Marcos (orgs) Desenvolvimento Rural: tendências e debates contemporâneos. ljuí: Ed: Unijuí, 192p., 2006

COSTABEBER, J. A. Acción colectiva y procesos de transición agroecológica en Rio Grande do Sul, Brasil. Córdoba, 1998. (Tese de Doutorado) Programa de Doctorado en Agroecología, Campesinado e Historia, ISEC-ETSIAN, Universidad de Córdoba, España, 1998. 422p.

COSTA, M. B. B da ., A agricultura moderna e sua crítica: uma saída em relação às vertentes da agricultura alternativa. In: Seminário de Pesquisa em Agricultura Alternativa, Anais.., Londrina, IAPAR, 1984.

DEL PINO, M. Certification: como encontrar una alternativa apropriada localmente? Hoja a hoja del Maela, 4 (6), 1994. 
DIAS, C. Movimentos sociais e agricultura alternativa. In I Seminário regional de agricultura alternativa. Anais.., Lavras: Feab Regional 3, 1986.

DIAS, M. M.; Diesel, V. A proposta das ONG brasileiras para o desenvolvimento rural; uma avaliação crítica. In: X World Congress of Rural Sociology, Anais.., Rio de Janeiro, 2000.

DO CARMO, M. S. La productiuon familiale como locus idéal de lagriculture durable. In: Zanoni, M.; Lamarche, H. (coord). Agriculture et ruralité au Brésil; un autre modèle de developpement. Paris: Karthala, 2001.

DULLEY, R. et al. Passado, ações presentes e perspectivas futuras da AAO Associação de Agricultura Orgânica. In: X World Congress of Rural Sociology, Anais.., Rio de Janeiro, 2000.

III Ebaa - Encontro Brasileiro de Agricultura Alternativa. Anais. Cuiabá: Faeab/Feab, 1987.

EHLERS, E. Agricultura sustentável; origens e perspectivas de um novo paradigma. São Paulo: Livros da Terra, 1996.

FIORIT, L. A produção e consumo de alimentos orgânicos como construção social da natureza natural. In: X World Congress of Rural Sociology, Anais.., Rio de Janeiro, 2000.

FONSECA, M. F. A C.; FELICONIO, A. E. G. A rede de produção e comercialização de alimentos orgânicos in natura no Brasil: avanços e retrocessos. In X World Congress of Rural Sociology, Anais.., Rio de Janeiro, 2000.

INSTITUTO BRASILEIRO DE GEOGRAFIA E ESTATÍSTICA. Índices. Disponível em:

www.ibge.gov.br/home/.../censoagro/2006/default.shtm 
JUNQUEIRA, A.H.; LUENGO, R.F.A. de. Mercados diferenciados de hortaliças. Horticultura Brasileira, Brasilia- DF, v.18, n.18, p. 95-99, 2000.

LAZZARINI, S. G. Estudos de caso para fins de pesquisa: Aplicabilidade e limitações do método. In: FARINA, E. (Coord.). Estudos de Caso em Agribusiness. São Paulo: Pioneira, 1997.

LOVATO, P. E. Agricultura Familiar, Agroecologia e Relações de. Gênero. Revista Brasileira de Agroecologia. v.2, n.1, 2007

MATTAR, F. N. Pesquisa de Marketing - Metodologia, Planejamento, Execução e Análise. São Paulo, Editora Atlas, Vol. I, 1993.

MEIRELLES, L. Certificação e dominação. Ipê: CAE-Ipê, sd.. 4p 2001.

MEIRELLES, L. Soberania Alimentar, Agroecologia e Mercados Locais. Revista Agriculturas. Rio de Janeiro v. 1, nº. 0, vol. 11-14, Set.,2004.

MESQUITA, Z. Agricultores e consumidores de produtos orgânicos: uma aproximação necessária In: Congresso Brasileiro de Agroecologia, 1, Anais.., Porto Alegre, RS, 2003.

MINISTÉRIO DA AGRICULTURA. Consumo de orgânicos leva mercado interno a crescer 40\% em 2010. Disponível em:

http:/ /www.brasil.gov.br/noticias/arquivos/2011/02/03/consumo-deorganicos-leva-mercado-interno-a-crescer-40-em-2010. Acesso em 22 ago. 2011

ORGANICS BRASIL http://www.organicsbrasil.org Acesso em 10 mar. 2011

OliVetTe, M. P. de A., NOGUeIRA, E. A., MELLO, N. T. C. de. Emprego e renda: $O$ processo participativo como instrumento para 0 desenvolvimento regional. São Paulo, SP. Revista Informações Econômicas, v. 30, n. 10, Outubro-2000. 
PINHEIRO, S. et al. A agricultura ecológica e a máfia dos agrotóxicos no Brasil. Porto Alegre: Ed. dos autores, 1993.

REDE TA-SUL - Rede Tecnologias Alternativas Sul. Interconectando idéias e ideais na construção da agricultura do futuro. In Almeida, J.; Navarro, Z. (org) Reconstruindo a agricultura; idéias e ideais na perspectiva do desenvolvimento rural sustentável. Porto Alegre: EdUFRGS, 1997.

RIO GRANDE DO SUL. Secretaria da Agricultura e Abastecimento. Centro Nacional da Pesquisa do Trigo. Macrozoneamento agroecológico e econômico do Estado do Rio Grande do Sul. v. 2.Porto Alegre, 1994.

ROSSETTI, E.K.; DE BEM, J.S. A Agroecologia no Estado do RS: perspectivas e resultados no Rio Grande do Sul (2002 a 2004).

Disponível em: http://www.scielo.br/pdf/eagri/v29n1/a16v29n1.pdf. Acesso em 22 ago.2011.

SALDANHA, L. J. Relato da construção de integração entre as ONG's históricas brasileiras ligadas à agricultura orgânica e do processo participativo de elaboração do texto das normas dos produtos orgânicos junto ao MARA. Porto Alegre, 1999. 3p.

SANTOS, L. C. R dos. Criada em SC a Rede Ecovida de Agroecologia. Agroecologia em Santa Catarina. 1(2), 4-5, 1999.

SANTOS, Hetel Leepkaln dos. Construção Social de Mercado Orgânico: O Caso da Cooperativa Ecoserra na Serra Catarinense. 2006. $117 \mathrm{f}$. Dissertação. (Mestrado) Programa de Pós-graduação em Agroecossistemas, Universidade Federal de Santa Catarina, Florianópolis, 2006.

SAMPIERI, R. H.; COLLADO, C. F.; LUCIO, P. B. Metodologia de la Investigación. México: Panamericana Formas e Impressos S.A., 1994. 
SCHMIDT, W. Agricultura orgânica; entre a ética e o mercado. Revista Agroecologia e Desenv.Rur.Sustent., Porto Alegre, v.2, n.1, jan./mar.2001

SCHMIDT, W. et al. Desenvolvimento local em espaços rurais; a construção de um território nas Encostas da Serra Geral, em Santa Catarina. In Paulilo, M.I.; Schmidt, W. (org.) Agricultura e Ruralidade em Santa Catarina. Florianópolis: EdUFSC, 2001.

SCHMITT, Claudia Job. Tecendo as redes de uma nova agricultura: um estudo socioambiental da Região Serrana do Rio Grande do Sul. 2001. 395 f. Tese (Doutorado em Sociologia) - Programa de Pós-Graduação em Sociologia, Instituto de Filosofia e Ciências Humanas, Universidade Federal do Rio Grande do Sul, Porto Alegre, 2001.

SCHIMITT, C. J. Transição para a Agroecologia na Região Sul. In: Encontro Nacional de Agroecologia, 2002, Rio de Janeiro.

SCHULTZ, Glauco. As cadeias produtivas de alimentos orgânicos do município de Porto Alegre/RS frente à evolução das demandas do mercado: lógica de produção e/ou de distribuição. 2001. $185 \mathrm{f}$. Dissertação (Mestrado) Programa de Pós-Graduação em Agronegócios, Universidade Federal do Rio Grande do Sul, Porto Alegre, 2001

SCHULTZ, Glauco. Relações com o Mercado e (Re) Construção das Identidades Socioprofissionais na Agricultura Orgânica. 282f. 2006. Tese (Doutorado em Agronegócios), Centro de Estudos e Pesquisas em Agronegócios, Universidade Federal do Rio Grande do Sul, Porto Alegre, RS, 2006.

SILVEIRA, C. A. da, ALMEIDA, J. Tendências na regulamentação da agricultura orgânica: um estudo comparativo dos casos da Califórnia setentrional e da Região Sul do Brasil. In: X World Congress of Rural Sociology, Anais.., Rio de Janeiro, 2000.

SILVEIRA, P. R. C. da, GUIMARÃES, G. M., FROELICH, J.M. e SULZBACHER,A.W. Da Identidade Cultural a Identidade Territorial: o 
Processo de Valorização do Saber Local como Estratégia de Desenvolvimento Regional, IV Congresso Argentino e Latino-Americano de Antropologia Rural, Mar Del Plata, Março 2009.

SILVEIRA, Paulo Roberto Cardoso da. Alimentos e Bebidas Orgânicas na Comensalidade Contemporânea: Um Estudo a Partir dos Processados Orgânicos no Rio Grande do Sul - Brasil. 2010. 201f. Tese (Doutorado) - Programa de Pós-Graduação Interdisciplinar em Ciências Humanas, Centro de Filosofia e Ciências Humanas, Universidade Federal de Santa Catarina. Florianópolis, 2010.

STORCH, G.; SILVA, F.F. da; BRIZOLA, R.M. de O.; AZEVEDO, R. de; VAZ, D. da S.; BEZERRA, A.J.A. Caracterização de um grupo de produtores agroecológicos do sul do Rio Grande do Sul. Revista Brasileira de Agrociência, Pelotas, v.10, n. 3, p. 357-362, 2004.

TEIXEIRA, S. S.; MACHADO, A. L. T.; REIS, Â. V. dos \& OLDONI, A. Caracterização da produção agroecológica do sul do Rio Grande do Sul e sua relação com a mecanização agrícola. Eng. Agríc. [online]. 2009, vol.29, n.1, pp. 162-171.

YIN, R.K. Case Study Research: Desidn and Methods. Newbury Park: Sage Publications, 1990.

Submetido em

Aprovado em 


\section{Sobre os autores}

\section{Fabio Schwab do Nascimento}

Professor do Instituto Federal do Paraná. Mestre em Agroecologia e Desenvolvimento Rural da Universidade Federal de São Carlos.

Endereço: Rua Fortaleza, Quadra 59, Lote 31, Residencial Ravena Apto 403 - Bairro Belo Horizonte. 68.503-560 - Marabá - Pará - Brasil.

E-mail: fabio.schwab@gmail.com

\section{Paulo Roberto Beskow}

Docente da Universidade Federal de São Carlos.

Endereço: Rua Alberto de Salvo, 238.13.084-759 - Campinas - SP - Brasil.

E-mail: prbeskow@yahoo.com.br 